\title{
Bimaterial Composites via Colloidal Rolling Techniques: III, Mechanical Properties
}

\author{
Mohan Menon ${ }^{*}$, \\ Department of Materials Science and Engineering, University of Michigan, Ann Arbor, Michigan 48109-2136
}

I-Wei Chen*

Department of Materials Science and Engineering, University of Pennsylvania, Philadelphia, Pennsylvania 19104-6272

The mechanical properties of layered Ce-TZP/Al ${ }_{2} \mathrm{O}_{3}$ composites with laminate and cellular morphologies have been investigated. The strength and toughness increase as the layer thickness decreases, and the amount of transformation in the Ce-TZP layer increases discontinuously at the laminate/cellular transition. Very high strengths (1.1 GPa) and toughnesses $\left(16 \mathrm{MPa} \cdot \mathrm{m}^{1 / 2}\right)$ have been obtained in some cases. These results indicate that the progressive refinement of layer microstructure and the disruption of planar connectivity of phases are beneficial to the mechanical performance, because they provide more stress concentrators to trigger stress-assisted transformation for toughening functions. The composites of finer microstructure, with a layer thickness of $\leq \mathbf{2 0} \boldsymbol{\mu m}$, have a homogeneous hardness of 11.5 GPa, which is a considerable improvement over that of Ce-TZP alone.

\section{Introduction}

$\mathrm{M}$ ODELS for the transformation toughening of zirconia ${ }^{1-4}$ predict that the toughness increases as the transformation-zone height in the wake of the crack increases. In materials such as ceria-stabilized tetragonal zirconia polycrystals (Ce-TZP), however, the transformation is highly overdriven and proceeds in an autocatalytic manner. ${ }^{5}$ This activity causes the transformation to spread unstably over macroscopic dimensions and the crack to follow the transformed microstructure to immediate failure. As a result, Ce-TZP has only relatively low strength, despite its impressive transformation plasticity and toughness. One way to mitigate this problem is to introduce physical barriers to limit the transformation zone. This method was first realized by Tsukuma et al., ${ }^{6}$ who used dispersed $\mathrm{Al}_{2} \mathrm{O}_{3}$ to achieve higher strength and hardness in Ce-TZP. Subsequent work by Cutler et al. ${ }^{7}$ further demonstrated the utility of this approach. The other way of achieving a larger transformation zone without encountering instability in crack growth is to force the zone to spread laterally normal to the crack-growth direction by imposing a layer of another material in the zirconia matrix. This procedure has been demonstrated by Marshall and co-workers. ${ }^{8,9}$ The fracture toughness of Ce-TZP was en-

D. S. Wilkinson-contributing editor

\footnotetext{
Manuscript No. 190324. Received March 16, 1998; approved June 21, 1999.

This research was supported by the U.S. Dept. of Energy (Basic Energy Sciences, BES), through a grant awarded to the University of Pennsylvania (Grant No. DEFG02-97ER45367-A000)

Member, American Ceramic Society.

${ }^{\dagger}$ Now at Dept. of Materials Science and Engineering, University of Illinois, Urbana, IL 61801 .
}

hanced by the introduction of an $\mathrm{Al}_{2} \mathrm{O}_{3}$ layer, which forces the transformation zone to spread along the Ce-TZP/Al ${ }_{2} \mathrm{O}_{3}$ interface. A toughness of $17.5 \mathrm{MPa} \cdot \mathrm{m}^{1 / 2}$ was observed in this material, along with extensive $R$-curve behavior, compared to a baseline value of $5 \mathrm{MPa} \cdot \mathrm{m}^{1 / 2}$ in monolithic Ce-TZP. Other experiments on $\mathrm{ZrO}_{2} / \mathrm{Al}_{2} \mathrm{O}_{3}$ composites that were performed by Lucchini and Sbaizero ${ }^{10}$ have indicated the presence of a compressive residual stress in the outer layer to be the reason for increased toughness and strength in the laminates. The flexural strength of these composites was highest when the residual stress was at its highest value, which was achieved when the outer layers were $\mathrm{Al}_{2} \mathrm{O}_{3}$-rich and the inner layer was at its thickest. However, the residual stress itself and its strengthening effect are expected to be diminished for multilayered composites.

The height of the spread zone of transformation observed by Marshall and co-workers ${ }^{8,9}$ was typically on the order of 300 $\mu \mathrm{m}$. If this is the upper boundary of the transformation height normal to the crack plane, then, in theory, only a coherent length of this order of magnitude is required for the zirconia layer to attain maximum toughness. Beyond this length, the zirconia phase may as well be discontinuous. Therefore, the same toughness enhancement can be achieved in a discontinuous layer composite that has a sufficiently long coherent length. In addition, the thickness of the layer should be irrelevant, as also observed by Marshall and co-workers. ${ }^{8,9}$ They performed stable-crack-growth experiments using $\mathrm{Al}_{2} \mathrm{O}_{3} / \mathrm{Ce}-\mathrm{TZP}$ composites with Ce-TZP layers of different thickness (35-70 $\mu \mathrm{m})$. No significant difference in the toughness or $R$-curve behavior was evident. These theoretical arguments suggest that cellular composites may be a viable alternative to layered composites. As was demonstrated in two previous papers (hereafter referred to as papers $\mathrm{I}^{11}$ and $\mathrm{II}^{12}$ ), in a cellular material, the zirconia is distributed inhomogeneously but still maintains a coherent length of at least $40 \mu \mathrm{m}$ at a thickness of $4 \mu \mathrm{m}$. Therefore, the transformation zone can be expected to be quite extended within such layers and high toughness might be obtained. In addition, microstructure irregularities in the cellular composites may help to promote crack branching and deflection or enhance transformation by providing stress concentrators, thereby achieving a high toughness and strength. This prospect has been explored in the present work, and promising results have been obtained.

As reported in papers $\mathrm{I}^{11}$ and $\mathrm{II},{ }^{12}$ we have developed a series of bimaterial Ce-TZP/Al $\mathrm{O}_{3}$ composites with laminate and cellular microstructures, using colloidal rolling and folding techniques. These composites have easily tailored microstructures, in terms of phase connectivity and layer thickness, and possess excellent sintering characteristics, in comparison to conventional layered composites. In this paper, the mechanical behavior of composites that have been fabricated using the rolling technique is characterized as a function of microstruc- 
ture. Flexure-strength tests, $R$-curve measurements, and indentation tests were performed at several temperatures to determine the mechanical properties of the composite. X-ray diffractometry (XRD) also was used, to correlate the extent of the stress-assisted transformation of Ce-TZP to mechanical performance. All the measured properties changed relative to the microstructure transition, and the cellular materials possessed superior properties.

\section{Experimental Procedure}

\section{(1) Materials}

All the specimens chosen for mechanical characterization were prepared using the colloidal rolling and folding method that has been described in paper I. ${ }^{11}$ They were folded at least six times, then fired to almost full density at $1600^{\circ} \mathrm{C}$. As shown in papers $\mathrm{I}^{11}$ and II, ${ }^{12}$ these composites have a layer of thickness of $<60 \mu \mathrm{m}$, and no microcracks that are due to sintering or cooling exist. For further details of the processing and microstructure characterization, refer to papers $\mathrm{I}^{11}$ and II. ${ }^{12}$

Three sets of samples were tested. Sample set A refers to composites that maintain a laminate geometry down to a layer thickness of $25 \mu \mathrm{m}$, beyond which it breaks down into a cellular geometry, with $\mathrm{ZrO}_{2}$ being the encased phase. Sample set $\mathrm{B}$ refers to composites that maintain a laminate geometry down to $70 \mu \mathrm{m}$, with $\mathrm{Al}_{2} \mathrm{O}_{3}$ being the encased phase in the finer, cellular microstructure. Sample set $\mathrm{C}$ refers to a composite that maintains a laminate geometry down to $40 \mu \mathrm{m}$; at a finer scale, it becomes cellular, with $\mathrm{ZrO}_{2}$ being the encased phase. The above-described sample designations are the same as those in papers $\mathrm{I}^{11}$ and II. ${ }^{12}$

Mechanical considerations dictate that better strength and toughness can be expected when the crack propagates from one layer to another. Figure 1 shows that there are two such crack configurations: $x$-plane and $z$-plane. (The crack always propagates in the $y$-direction). Therefore, we have measured the corresponding strengths in both the $z$ - and $x$-directions, in addition to the $R$-curves along the $x$-plane. The above-given convention also is the same as those used in papers $\mathrm{I}^{11}$ and II. ${ }^{12}$

\section{(2) Strength Measurements}

Strength in the z-direction, as depicted in Fig. 1, was measured using specimens with dimensions of $17 \mathrm{~mm} \times 3 \mathrm{~mm} \times 1$ $\mathrm{mm}$. Their tensile surfaces were polished to a $6 \mu \mathrm{m}$ finish after cutting and grinding. During grinding, cutting, and polishing, zirconia on the surface was expected to transform to the monoclinic phase. Therefore, before testing, all the samples were annealed at $1200^{\circ} \mathrm{C}$ to convert the zirconia back to the tetragonal phase. Then, these samples were fractured in a three-point flexure configuration on a servohydraulic testing machine (Model 810, Materials Testing Systems, Minneapolis, MN). These experiments were conducted at room temperature and at $-50^{\circ} \mathrm{C}$, which is just above the martensitic tetragonal/ monoclinic transition temperature $\left(M_{\mathrm{s}}\right)^{13}$ for sample $\mathrm{B}$. Samples A and $\mathrm{C}$ were fractured using the same procedure at room temperature.

Strength in the $x$-direction also was measured. For this purpose, samples with dimensions of $20 \mathrm{~mm} \times 4 \mathrm{~mm} \times 1 \mathrm{~mm}$ were used. These samples were used previous for the $R$-curve measurements that are described below. Before testing, these samples also were annealed at $1200^{\circ} \mathrm{C}$ to convert any monoclinic zirconia to the tetragonal phase.

\section{(3) R-Curve Specimens}

For the $R$-curve measurements, the specimen was notched such that the crack ( $x$-plane) was oriented normal to the layers. Then, the load was applied in the $y$-direction and the crack propagated in this direction. Fired samples were ground and specimens with dimensions of $40 \mathrm{~mm} \times 1 \mathrm{~mm} \times 4 \mathrm{~mm}$ were cut, with two sides polished to a $6 \mu \mathrm{m}$ diamond finish. The chosen dimensions were much greater than the width of the

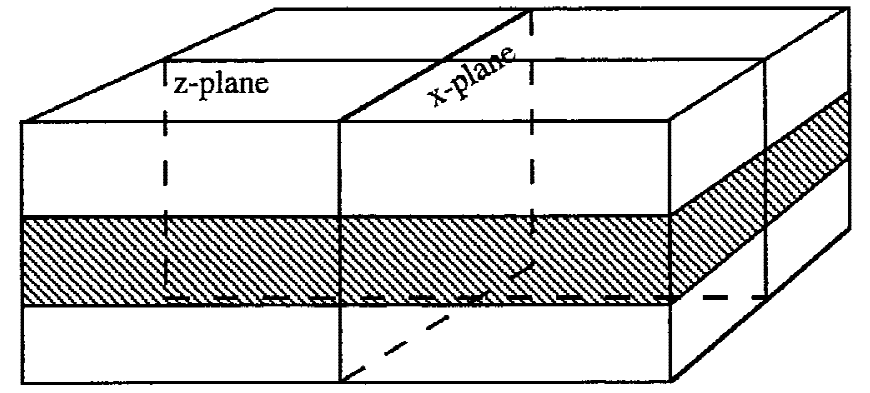

(a)

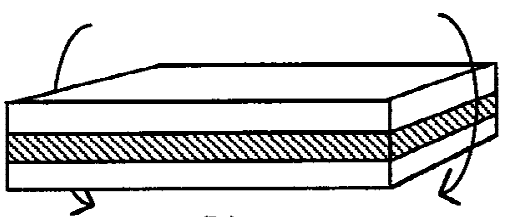

(b)

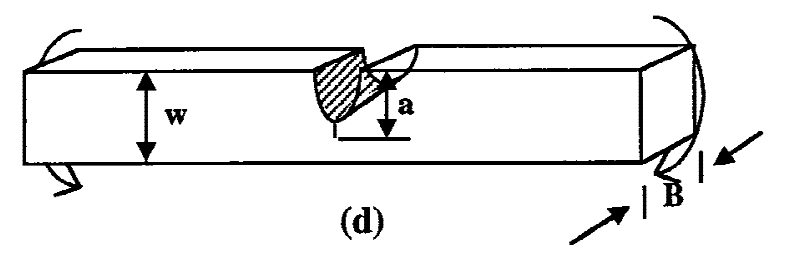

Fig. 1. Schematic of specimen configurations ((a) specimens cut along parallel $x$-planes or $z$-planes of a rolled plate, (b) bend bar for strength in the $x$-direction, (c) bend bar for strength in the $z$-direction, and (d) half-chevron-notched $R$-curve specimen). Rolling is along the $x$-direction.

transformation zone that was reported for similar material by Marshall and co-workers. ${ }^{8,9}$ Thus, all the $R$-curve measurements were made in plane-strain conditions. To obtain a stable configuration for crack initiation, a half-chevron notch was made, as shown in Fig. 1, using a diamond wafer blade. The notch had a depth of $1 \mathrm{~mm}$ (the longer side) and a width of 200 $\mu \mathrm{m}$. Then, the specimens were annealed at $1200^{\circ} \mathrm{C}$ to reconvert the surface zirconia to the tetragonal phase.

A stable crack was grown from the root of the notch, using a screw-driven loadframe (Model 4483, Instron, Danvers, MA) with three-point loading through rollers. Displacement of the sample was monitored by a deflectometer that was placed at the notch, as shown in Fig. 2. The displacement of the deflectometer was monitored using a linear voltage displacement transducer (LVDT). The load was monitored using a $5 \mathrm{kN}$ load cell. Precracking was done, under displacement control, at a rate of $0.5 \mathrm{~mm} / \mathrm{s}$. Load and displacement outputs were monitored during the test. Figure 2 shows that the test was stopped when the load-displacement curve deviated from linearity. Then, the specimen was visually checked for a sharp crack via optical microscopy. Specimens used for $R$-curve measurements were selected from those that had a straight precrack that started at the root of the notch, such as that shown in Fig. 3.

\section{(4) Crack-Growth Measurements}

The precracked sample was annealed again to reconvert the transformed zirconia near the crack tip to the tetragonal phase. A standard three-point loading configuration through rollersthe same as that for the precracking experiments - was used for subsequent crack-growth experiments. The crack length was measured via the compliance method. This method exploits the fact that the compliance of the specimen is a strong function of the crack length. The compliance of the specimen can be ob- 


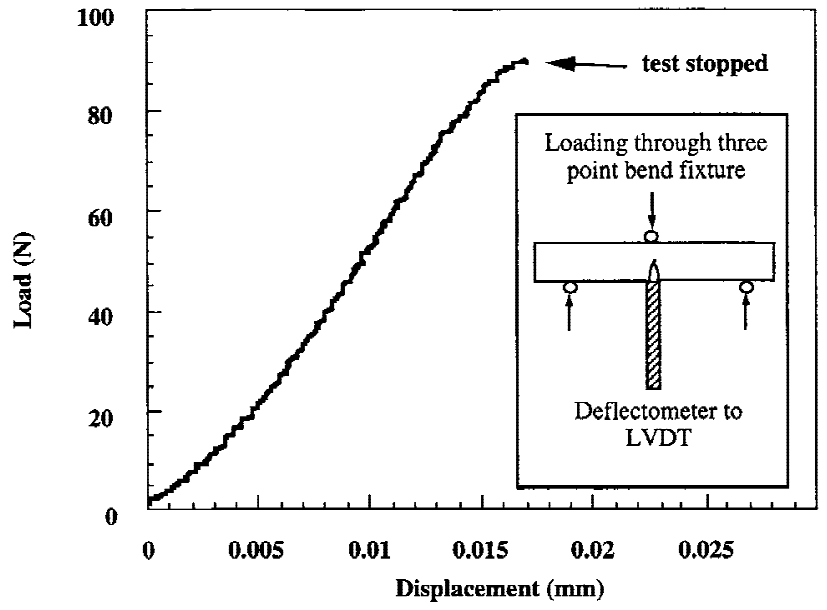

Fig. 2. Typical load-displacement curve obtained from the loading geometry for precracking (shown schematically in the inset); the test was stopped when the load-displacement curve became nonlinear.

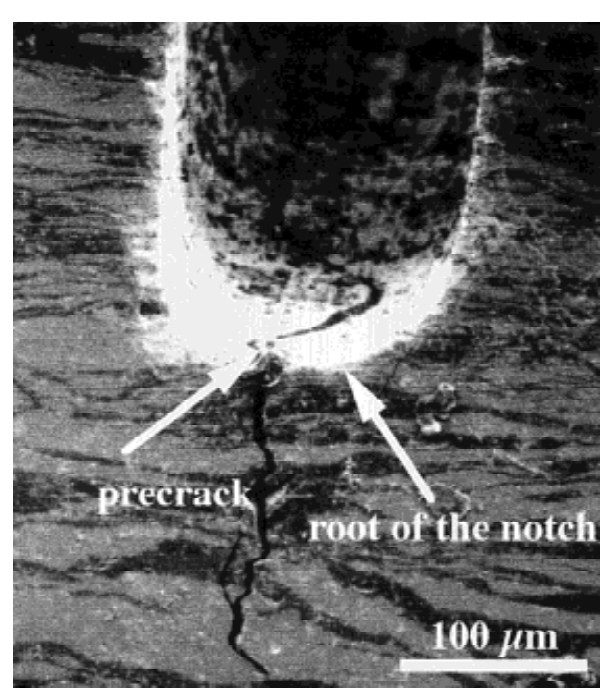

Fig. 3. Micrograph showing a precrack at the root of a notch.

tained by subtracting the machine compliance from the compliance that is measured from the load-displacement curves. Typically, the specimen was loaded until the loaddisplacement curve deviated from linearity. Then, the specimen was unloaded to a low load $(10-20 \mathrm{~N})$ before reloading to a higher load (see Fig. 4(a)). This loading/unloading cycle was performed until the crack grew unstably. In all our experiments, however, we could unload the specimens so that the unstable cracks were arrested and the specimen was still in one piece after the test.

After correcting for the machine compliance, one can calculate the crack length from the unloading compliance, using the following equation: ${ }^{14}$

$$
\begin{aligned}
C= & \frac{P s^{3}\left(1-v^{2}\right)}{\Delta B E^{\prime} w^{3}}\left[0.25+0.6\left(\frac{w}{s}\right)^{2}(1-v)\right] \\
& +1.5\left(\frac{s}{w}\right)^{2}\left(\frac{\frac{a}{w}}{1-\frac{a}{w}}\right)\left(\frac{P}{\Delta B E^{\prime}}\right)\left[5.58-19.57\left(\frac{a}{w}\right)\right. \\
& \left.+36.82\left(\frac{a}{w}\right)^{2}-34.94\left(\frac{a}{w}\right)^{3}+12.77\left(\frac{a}{w}\right)^{4}\right]
\end{aligned}
$$

where $P$ is the peak load of the loading cycle, $w$ the width of
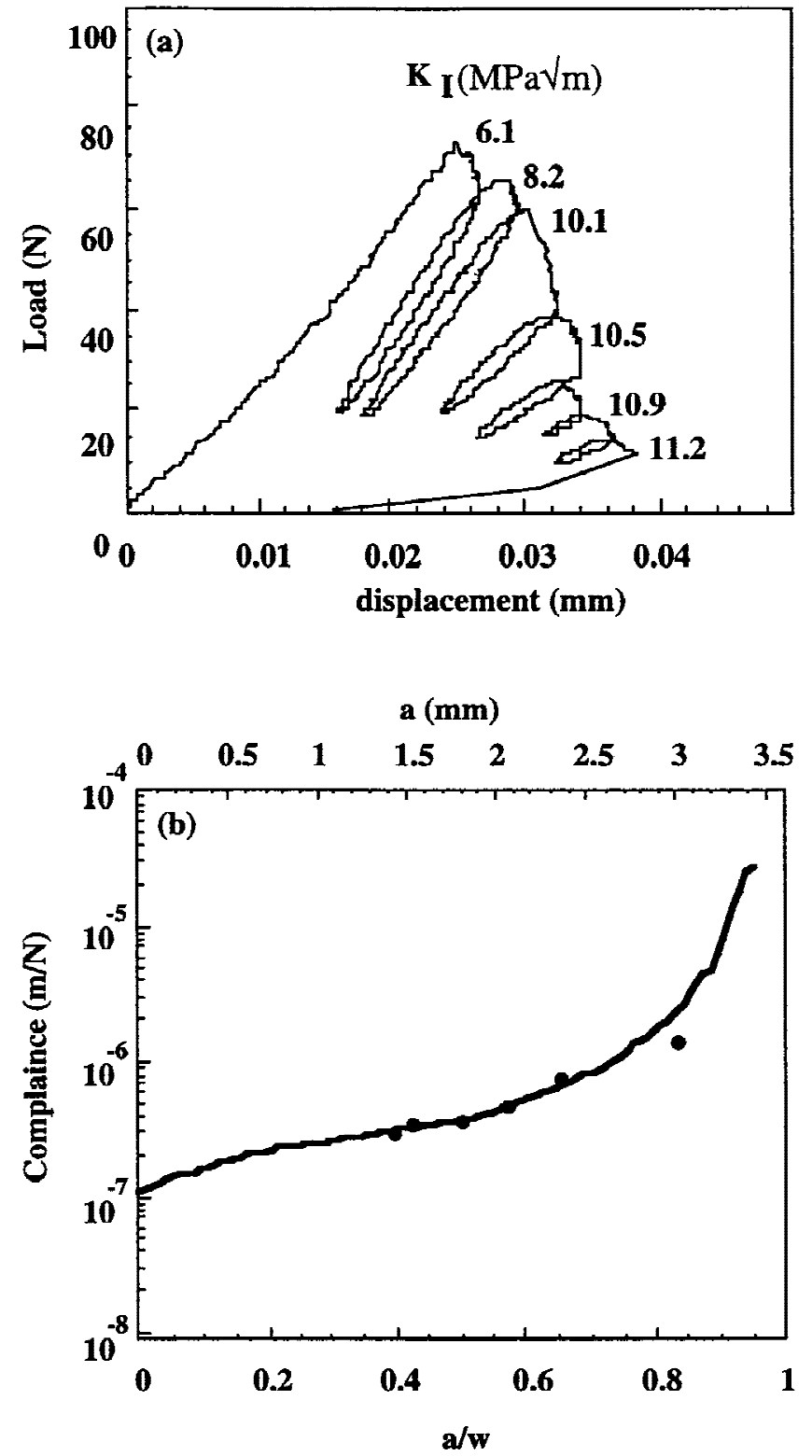

Fig. 4. Typical $R$-curve measurement technique ((a) loaddisplacement curve for load/unload cycles with the corresponding $K_{-}$ values (in units of $\mathrm{MPa} \cdot \mathrm{m}^{1 / 2}$ ) at the peak loads and (b) calculated compliance as a function of crack length). Measured compliance data from Fig. 4(a), after correcting for the machine compliance, are shown as filled circles. The crack length is measured optically.

the sample, $a$ the crack length, $s$ the span of the testing configuration, $B$ the breadth of the sample, $v$ the Poisson's ratio, $\Delta$ the total displacement of the specimen (given by the sum of the displacement of the specimen with a crack and the displacement of the specimen at load without a crack $\left(\Delta=\Delta_{\mathrm{c}}+\Delta_{\mathrm{nc}}\right)$, and $E^{\prime}$ the elastic constant under plane-strain conditions (related to the Young's modulus $E$ by $\left.E /(1-v)^{2}\right)$. These dimensions are shown in Fig. 1. Compliance was first calculated for each specimen and plotted as a function of crack length in Fig. 4(b). This plot was used to determine the crack length for the tested specimen, using the compliance at the peak. To test the accuracy of the compliance method, calibration experiments were performed via direct determination of the crack length after each load/unload cycle by removing the specimen from the test fixture to measure the crack length optically. This crack length is plotted against the measured compliance in Fig. 4(b). The agreement between the estimated and measured crack length is tolerable in the $a / w$ range of interest (up to 0.75 ). 
The fracture toughness $\left(K_{\mathrm{IC}}\right)$ was calculated as a function of crack length by using the following expression: ${ }^{14}$

$$
K_{\mathrm{IC}}=\frac{P s}{B w^{3 / 2}} f\left(\frac{a}{w}\right)
$$

where

$$
\begin{aligned}
f\left(\frac{a}{w}\right)= & 3\left(\frac{a}{w}\right)^{1 / 2}\left\{1.99-\left(\frac{a}{w}\right)\left(1-\frac{a}{w}\right)[2.15\right. \\
& \left.\left.-3.93\left(\frac{a}{w}\right)+2.7\left(\frac{a}{w}\right)^{2}\right]\right\} \\
& \times\left\{2\left[1+2\left(\frac{a}{w}\right)\right]\left[1-\left(\frac{a}{w}\right)\right]^{3 / 2}\right\}^{-1}
\end{aligned}
$$

The peak load and the compliance were measured and the $K_{\mathrm{IC}}$ values were computed until no stable crack growth was possible. To ensure reproducibility, these $R$-curve measurements were performed on two specimens for each material.

\section{(5) Phase Transformation}

The amount of zirconia transformation during a fracture event was quantified using XRD experiments that were conducted on the fracture surface. The samples were loaded in rotating-anode X-ray unit (Rigaku, Tokyo, Japan), and the fracture surfaces were irradiated using $\mathrm{CuK \alpha}$ radiation. The resultant XRD pattern was analyzed using JCPDS files for tetragonal and monoclinic zirconia. ${ }^{*}$ The fraction of monoclinic phase was estimated using the ratios of the integrated intensities below the tetragonal and monoclinic $\{111\}$ peaks:

$$
\% \text { transformed }=\frac{[11 \overline{1}]_{m}+[111]_{m}}{[11 \overline{1}]_{m}+[111]_{m}+[111]_{t}}
$$

Because of texturing, ${ }^{15,16}$ this expression overestimates the actual fraction of monodispersed phase and only provides a relative measure of the transformation in each sample. Nevertheless, this relation is adequate for the purpose of comparing transformation amounts in different samples.

\section{(6) Indentation Tests}

Samples for indentation tests were annealed at $1200^{\circ} \mathrm{C}$ to convert the monoclinic phase to the tetragonal phase. Indentation tests were conducted on a hardness tester (Zwick, East Windsor, CT), using a Vickers indenter. They were performed at both room temperature and at $200^{\circ} \mathrm{C}$, which is above the monoclinic-to-tetragonal phase-transformation temperature for fine-grained Ce-TZP. ${ }^{13}$ Crack growth from the indents was observed only at the higher temperature. Five measurements were made for each sample. The indentations were placed in the center of both the Ce-TZP layer and the $\mathrm{Al}_{2} \mathrm{O}_{3}$ layer, and the indents were made at a load of $10 \mathrm{~kg}$ for $20 \mathrm{~s}$. The hardness $H$ was calculated from the expression

$$
H=\frac{P}{2 a^{2}}
$$

where $P$ is the indentation load and $2 a$ is the diagonal length of the square indent.

The indentation toughness was calculated for samples that were indented at $200^{\circ} \mathrm{C}$. The toughness was estimated using the method of Anstis et al.:17

$$
K_{\mathrm{IC}}=0.019\left(\frac{E}{H}\right)^{1 / 2}\left(\frac{P}{c^{3 / 2}}\right)
$$

JCPDS Powder Diffraction File Card No. 24-1164 (tetragonal $\mathrm{ZrO}_{2}$ ) and No. 24-1165 (monoclinic $\mathrm{ZrO}_{2}$ ), Joint Committee on Powder Diffraction Standards (JCPDS), Swathmore, PA (now International Centre for Diffraction Data (ICDD), Newtown Square, PA) where $c$ is the crack length from the center of the square to the crack tip.

\section{Results}

\section{(1) Flexural Strength}

Figure 5(a) shows the strength of sample B tested at room temperature in two different directions. The strength is generally higher in the $z$-direction (perpendicular to rolling) than in the $x$-direction. This observation implies that the layer composites have an orthotrophic symmetry, despite the apparent similarity of microstructure as reported in Fig. 1. Figure 5(b) shows the flexural strength of composite samples A, B, and C as a function of $N$ at room temperature. The strength is generally highest in sample B and lowest in sample A. For the strongest set (sample B), the strength at $-50^{\circ} \mathrm{C}$, just above the martensitic burst temperature, also is shown. As indicated by these data, in general, the strength of the composite increases as $N$ increases (i.e., the layer thickness decreases). The composites are stronger at lower temperatures, presumably because of more transformation. The strength for ten foldings in sample B increases to $1.1 \mathrm{GPa}$ at $-50^{\circ} \mathrm{C}$ from $550 \mathrm{MPa}$ at room temperature.

\section{(2) Transformation}

To correlate strength with the tetragonal-to-monoclinic transformation, evidence for the transformation was sought on
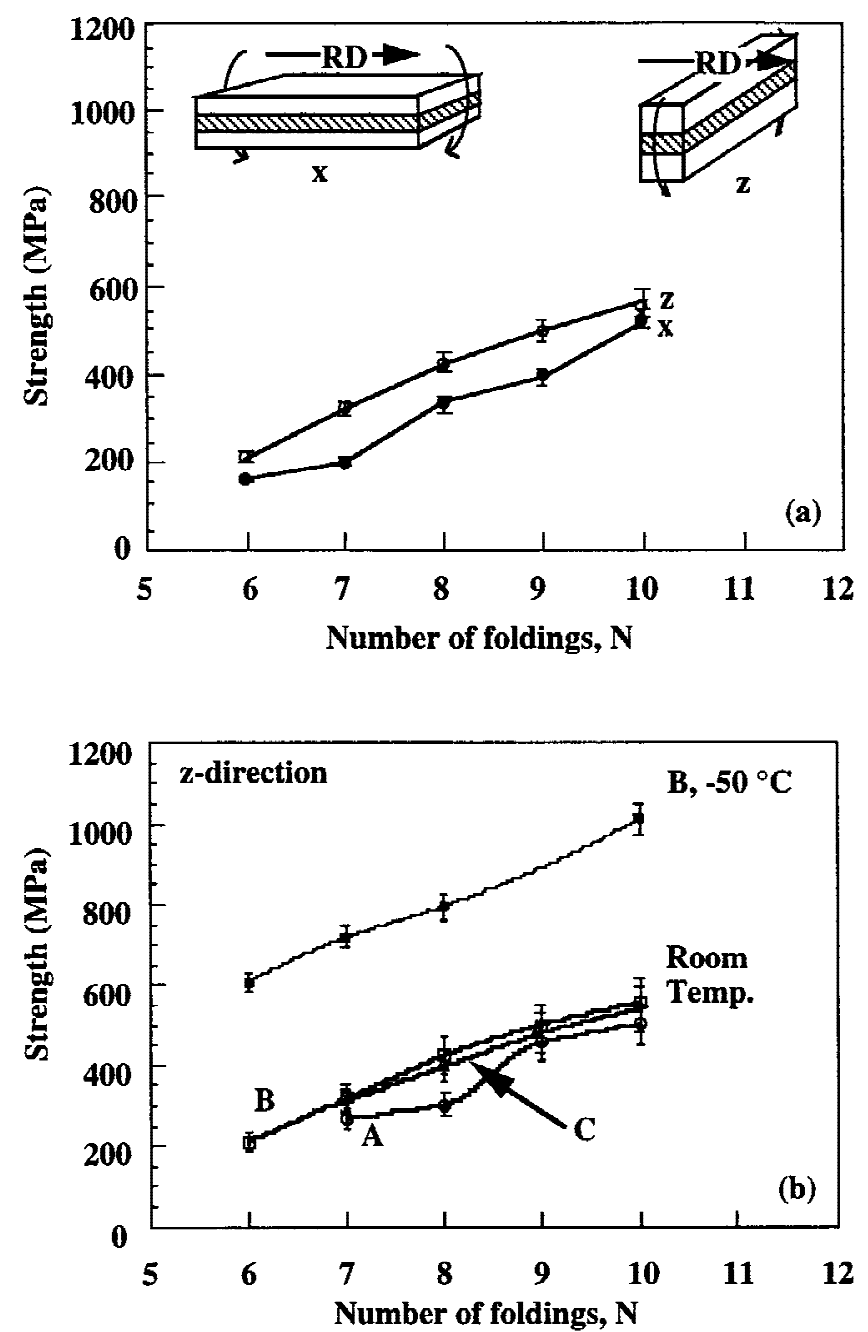

Fig. 5. (a) Flexural strength of sample B at room temperature parallel ( $x$-direction) and perpendicular ( $z$-direction) to the rolling direction; the strength increases monotonically as $N$ increases. (b) Flexural strength in the $z$-direction as a function of $N$ for samples A, B, and C at room temperature and for sample set $\mathrm{B}$ at $-50^{\circ} \mathrm{C}$. 
the side surface and the fracture surface. Optical techniques such as Nomarski interference failed to distinguish surface uplift that could have resulted from transformation. The polishing behavior of the two phases is different because Ce-TZP is softer than $\mathrm{Al}_{2} \mathrm{O}_{3}$, and, after polishing, the $\mathrm{Al}_{2} \mathrm{O}_{3}$ is raised in comparison to the Ce-TZP on the surface. This surface relief due to polishing made it difficult to discern surface uplift due to transformation on the complicated, wavy interface. As a result, XRD was used to estimate the amount of phase transformation on the fracture surface.

The amount of phase transformation during strength measurements is shown in Fig. 6. (These are the same specimens that were used for the $z$-plane strength data in Fig. 5(b). A systematic shift of the data curves to higher $N$ is observed for samples $\mathrm{B}, \mathrm{C}$, and $\mathrm{A}$ at room temperature. In these curves, the amount of transformation increases from $20 \%$ to $30 \%$, and the increase seems to coincide with the critical number of foldings for the microstructure transition $(N=6-7$ for sample $\mathrm{B}, N=$ 7-8 for sample C, and $N=8-9$ for sample A). ${ }^{11}$ This trend causes the amount of transformation to be generally greater in sample B compared to sample C, which, in turn, is greater than in sample A. Note that the same trend in the strength data is observed in Fig. 5. There also is a gradual increase of the amount of transformation after the transition, as the cellular microstructure becomes finer in scale. Again, this observation is consistent with the increasing strength of the material as the microstructure was refined.

Lastly, at low temperature, the amount of transformation increases for both layered and cellular materials, in comparison to that at room temperature. This increase is $\sim 10 \%$ and is quite substantial. It also corresponds to the considerable increase in strength. Indeed, as shown in Fig. 7, there is a general correlation between the amount of transformation and the strength. A higher strength results from a higher amount of transformation, which itself is dependent on the microstructure, including the scale and the phase connectivity.

\section{(3) Crack-Growth and R-Curve Behavior}

Figure 8 shows the sequence of crack growth from an $R$ curve measurement made on sample B folded six times, interrupted several times to obtain optical micrographs. After initiating stably from the notch (Fig. 8(a)), the crack grew unstably when the load was increased. However, the crack was arrested after $\sim 500 \mu \mathrm{m}$ of travel (Fig. 8(b)). Upon further loading, the

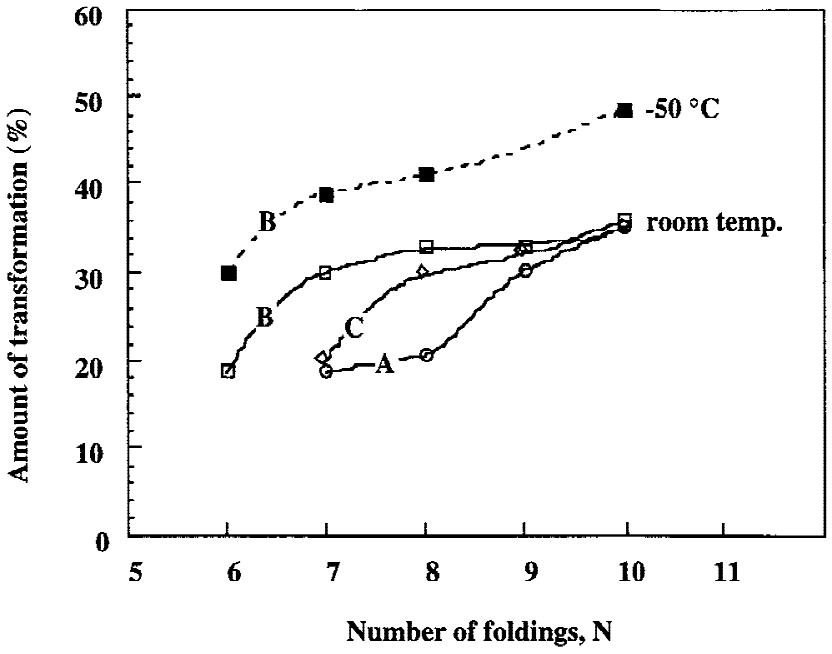

Fig. 6. Amount of transformation on the fracture surface for samples A, B, and C, as a function of $N$ (same samples as in Fig. 5(b)).

crack grew stably through the layers for $\sim 400 \mu \mathrm{m}$ (Fig. 8(c)). Further loading of the sample produced stable crack growth with very small increments in the crack length, apparently because of crack deflection at the phase interface (Fig. 8(d)). After an additional crack growth of $100 \mu \mathrm{m}$ in approximately five load increments, further loading produced an unstable crack growth of $500 \mu \mathrm{m}$ (Fig. 8(e)). However, the crack was arrested $\sim 600 \mu \mathrm{m}$ from the edge of the sample (Fig. 8(f)). The sample was still in one piece after the test. The critical stress intensity factor increased from $\sim 7 \mathrm{MPa} \cdot \mathrm{m}^{1 / 2}$ to $13.5 \mathrm{MPa} \cdot \mathrm{m}^{1 / 2}$ as the crack approached the edge of the sample.

Figures 9(a) and (b) show $R$-curves for samples A and B, respectively, as a function of $N$. Each of these $R$-curves consists of the average of the data for two measurements that were conducted to the point of unstable crack growth. The crack growth occurred in a similar fashion for the specimens, with the crack being arrested 400-600 $\mu \mathrm{m}$ from the edge of the sample (i.e., all the specimens were in one piece after the test, regardless of the shape of the $R$-curve). The slope of the $R$ curve and the maximum $K_{R}$ values seem to be dependent on $N$

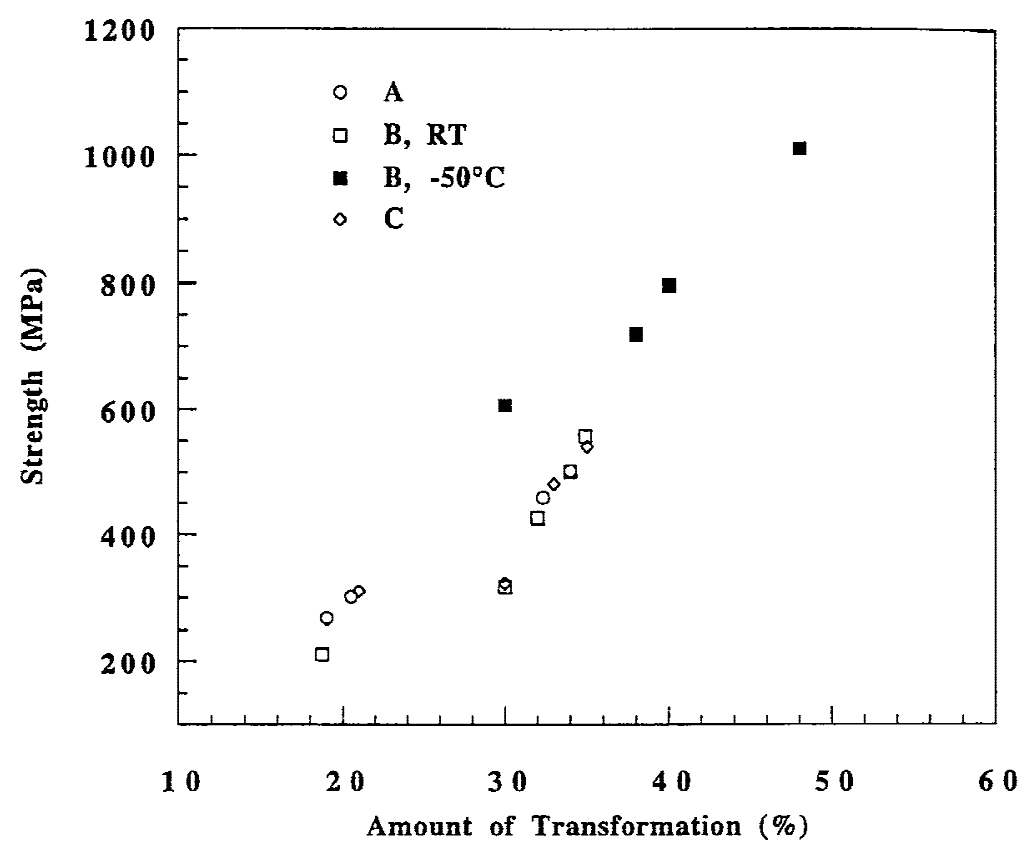

Fig. 7. Strength as a function of the amount of transformation for samples $\mathrm{A}, \mathrm{B}$, and $\mathrm{C}$ at room temperature and sample $\mathrm{B}$ at $-50^{\circ} \mathrm{C}$. 

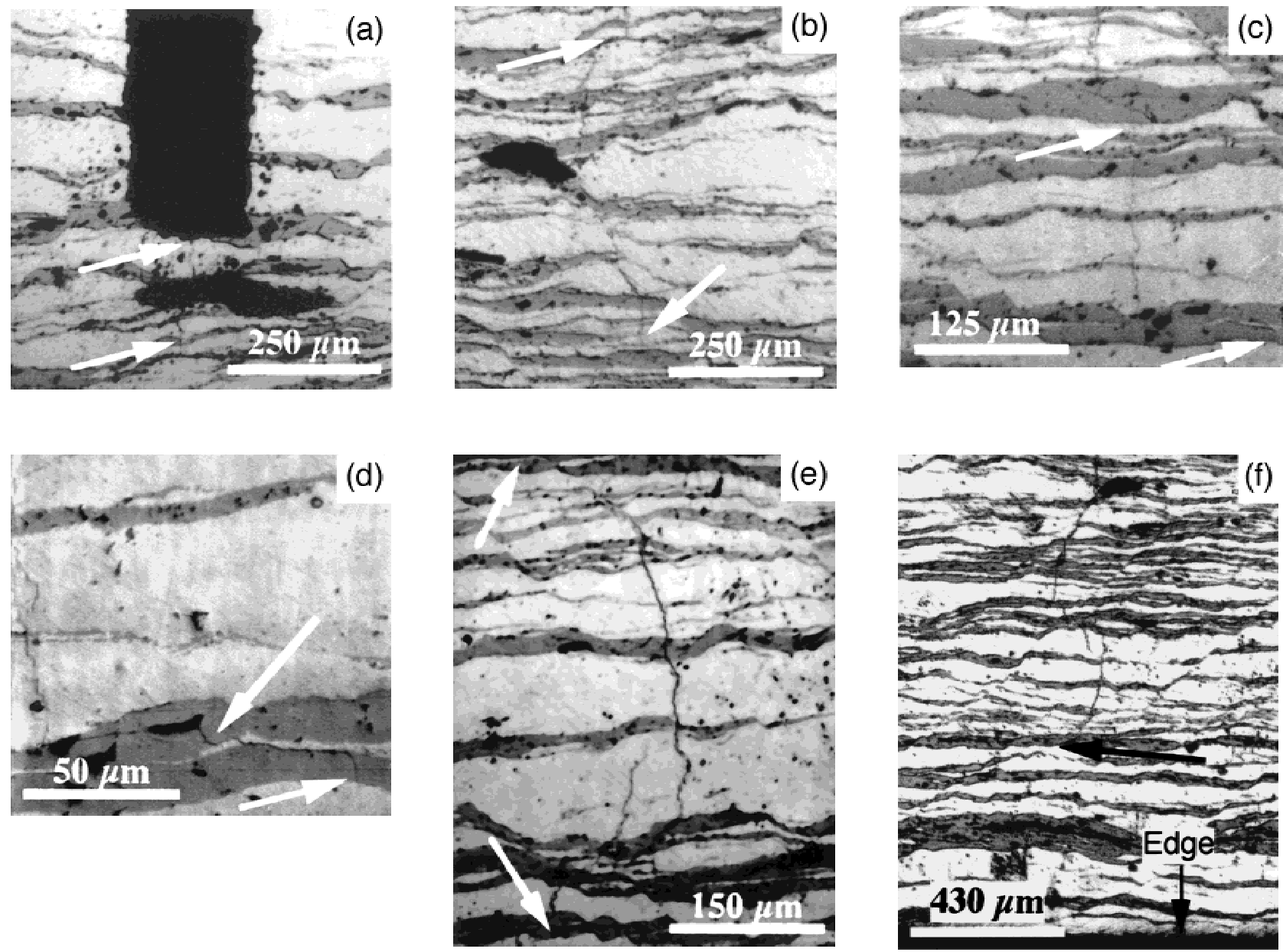

Fig. 8. Optical micrographs depicting the crack-growth sequence in sample B folded six times. Crack positions are marked by arrows. The crack path often zigzags (Figs. 8(b), (c), and (e)) and sometimes is deflected by a considerable distance (Fig. 8(d)). Crack branching also is visible (Fig. 8(e)). Figure 8(f) shows that the crack arrested before reaching the edge of the sample.

and the microstructure transition. To appreciate the general trend, we compare some of the $R$-curves in Fig. 10. (The curves in Fig. 10 have been displaced horizontally for clarity.) Figure 10(a) compares samples A and B at ten foldings, both with a cellular structure, and sample A at eight foldings and B at six foldings, both just before the layer-to-cellular transition. The cellular structure seems to give a steeper, almost-concaveupward $R$-curve, whereas the layered structure gives a shallower, concave-downward $R$-curve. After the transition is complete, increasing $N$ or decreasing thickness has a relatively smaller effect on the $R$-curve. This phenomenon can be observed, for example, in sample B, shown in Fig. 10(b), for $N=$ $7-10$, all in the cellular structure. In the layered microstructure, an increasing $N$ and decreasing layer thickness also seem to have only a small effect on the steepness and the peak value of the $R$-curve. This effect can be observed, for example, in sample A by comparing seven and eight foldings, both with the layered microstructure (see Fig. 9(a)).

The above-given data are somewhat limited, in that only three layered materials were characterized. The stability in crack-growth measurements in our experiments also limited the range of the $R$-curves in some cases. In addition, only $R$-curves of cracks on the $x$-plane that propagated in the $y$-direction have been obtained, whereas the presumably stronger $z$-plane was not investigated. Overall, however, the data suggest that the $R$-curves of the cellular materials are steeper, with higher peak values than those of the layered materials. Decreasing thickness has a tendency to have a similar effect, although the effect is less pronounced and is not entirely separable from that of the microstructure transition.

\section{(4) Indentation}

Indentations at room temperature showed no crack formation in our materials, which is a common observation for Ce-TZP. Figure 11 shows that the hardness value is dependent on the location of the indent for samples with a larger layer thickness, and the hardness of Ce-TZP is considerably lower than that of $\mathrm{Al}_{2} \mathrm{O}_{3}$. At smaller thicknesses, the average hardness values increase as the layer thickness decreases for all samples. A high homogeneous hardness of $11.5 \mathrm{GPa}$ is attained after nine foldings, which corresponds to a layer thickness of $15 \mu \mathrm{m}$ (see paper I). ${ }^{12}$

Indentations at $200^{\circ} \mathrm{C}$ showed radial cracks growing from the indents, which enabled calculation of the toughness of the composites. (At this temperature, transformation toughening is substantially lost. ${ }^{13}$ ) For thicker layers, the hardness again is dependent on the location of the indent. For thinner layers, where the indent encompasses more than one layer, the hardness values increased as the layer thickness decreased (see Fig. 12). The toughness results also are plotted in Fig. 12. The toughness increases from $4.8 \mathrm{MPa} \cdot \mathrm{m}^{1 / 2}$ to $5.5 \mathrm{MPa} \cdot \mathrm{m}^{1 / 2}$ as the thickness decreases.

Convergence of the hardness values in the different phase regions as the ratio of indent size to layer thickness increases has been observed previously by Mumm et al. ${ }^{18}$ Essentially, as the indent increases in size, it must deform both phases, sampling an average plastic-deformation resistance that is characteristic of the composite. This condition also is believed to be the case here. However, our hardness value converged to a higher value than that reported by Mumm et al., ${ }^{18}$ because, unlike previous investigators, we did not use a blended $\mathrm{Al}_{2} \mathrm{O}_{3} /$ 

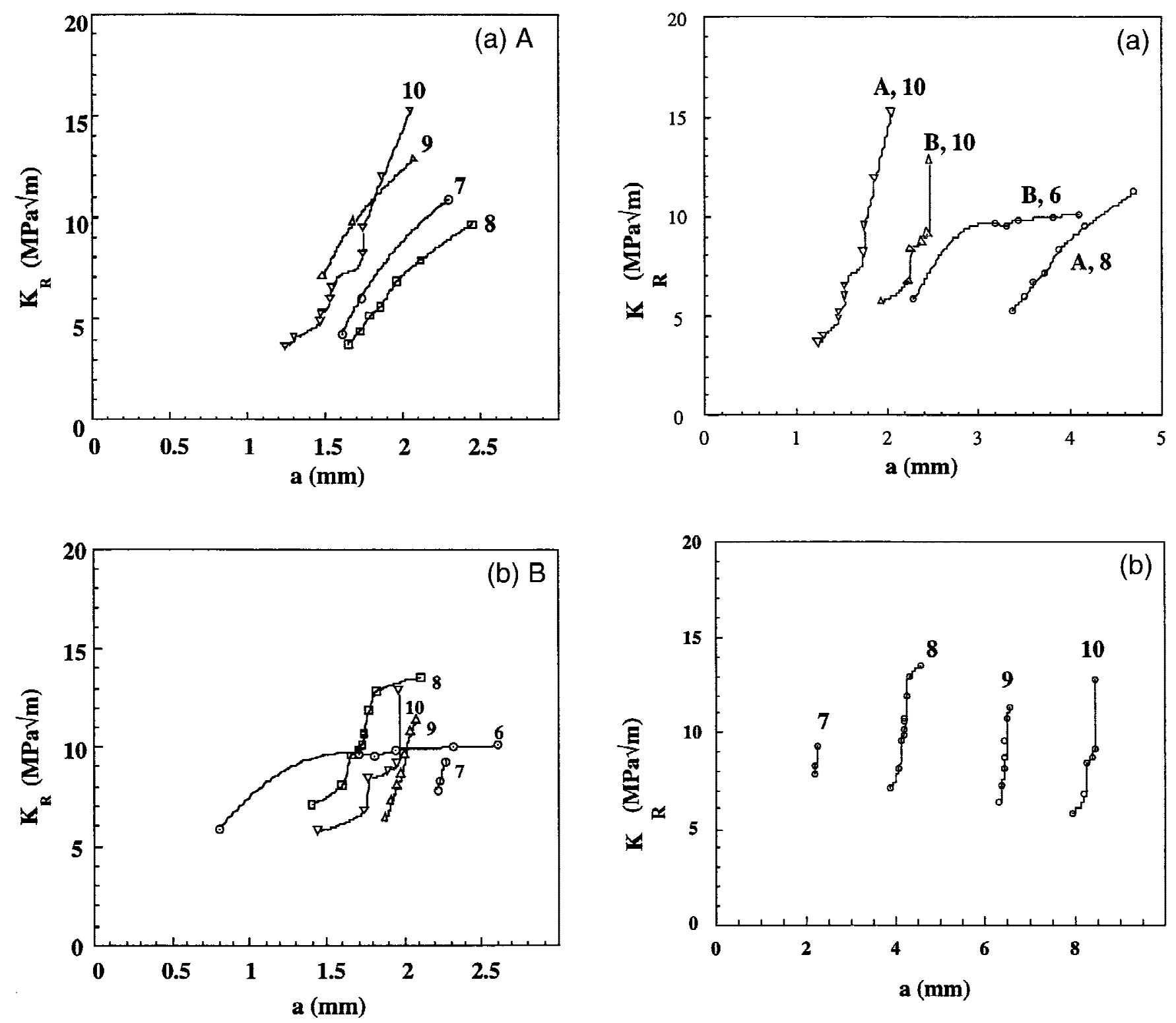

Fig. 9. $R$-curve for (a) sample $\mathrm{A}$ and (b) sample $\mathrm{B}$, as a function of $N$. Note the different curvatures and peak $K_{\mathrm{R}}$ values of the curves.

Fig. 10. $R$-curves for some layered and cellular material, replotted together for comparison purposes. The $R$-curve is steeper and attains higher $K$ values for cellular materials ((a) samples A and B, $N=10$, and (b) sample $\mathrm{B}, N=7-10)$ ). Curves are translated horizontally for clarity.

Ce-TZP layer for the nontransforming phase. $\mathrm{Al}_{2} \mathrm{O}_{3}$ is harder than $\mathrm{Ce}-\mathrm{TZP}$; therefore, the use of unblended $\mathrm{Al}_{2} \mathrm{O}_{3}$ increases the hardness of our composites.

\section{Discussion}

\section{(1) Transformation and Strength of $\mathrm{Ce}$-TZP/ $\mathrm{Al}_{2} \mathrm{O}_{3}$ Composites}

Referring to Figs. 6 and 10, there is a significant change in the amount of transformation and the $R$-curve at the microstructure transition. Thinner layers in general, and cellular microstructure in particular, seem to facilitate the transformation. The microstructure also affects the strength and the $R$-curve; however, the thickness effect seems to be smaller than the effect of the microstructure transition. The relatively small increase in the amount of transformation as the layer thickness decreases also was observed by Marshall and co-workers. ${ }^{8,9}$ They performed stable-crack-growth experiments with specimens that contained isolated thin layers of $\mathrm{Al}_{2} \mathrm{O}_{3} / \mathrm{Ce}-\mathrm{TZP}-$ one $35 \mu \mathrm{m}$ thick and the other $70 \mu \mathrm{m}$-in an $\mathrm{Al}_{2} \mathrm{O}_{3}$ matrix.

The widening of the transformation zone around the $35 \mu \mathrm{m}$ layer and the $70 \mu \mathrm{m}$ layer was similar in magnitude. Because the amount of transformation is apparently central to the mechanical performance of these composites, it is necessary to identify the key microstructure feature that triggers the transformation.

Our current understanding of Ce-TZP and its composites with $\mathrm{Al}_{2} \mathrm{O}_{3}{ }^{1,8,9}$ indicates three major factors that influence the size of the transformation zone: (i) physical barriers of nontransforming material, which force the spreading of the transformation zone; (ii) thermal residual stress, which influences the transformation driving force; and (iii) stress concentrators, which enhance the local driving force and activate the transformation nuclei. Studies that were conducted by Alexander et $a l .{ }^{19}$ on the effect of internal stresses on the transformation behavior of $\mathrm{Ce}-\mathrm{TZP} / \mathrm{Al}_{2} \mathrm{O}_{3}$ composites show that the residual stress in $\mathrm{Ce}-\mathrm{TZP}$ is tensile and aids the transformation. Folding and rolling in general, and the breakdown of the layer structure in particular, however, decrease the magnitude of the residual stress, because of plane bending and phase mixing, as dis- 


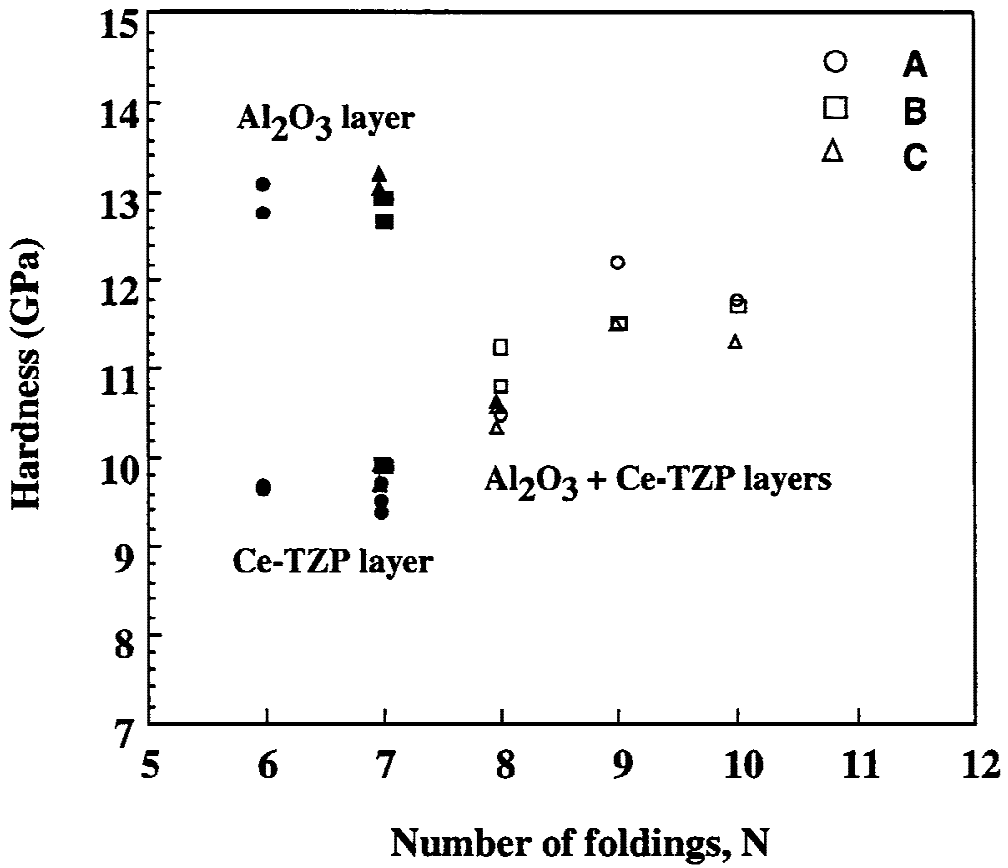

Fig. 11. Hardness as a function of $N$. Solid symbols represent the indents in single-phase layers, and open symbols are those which encompass both phase layers.

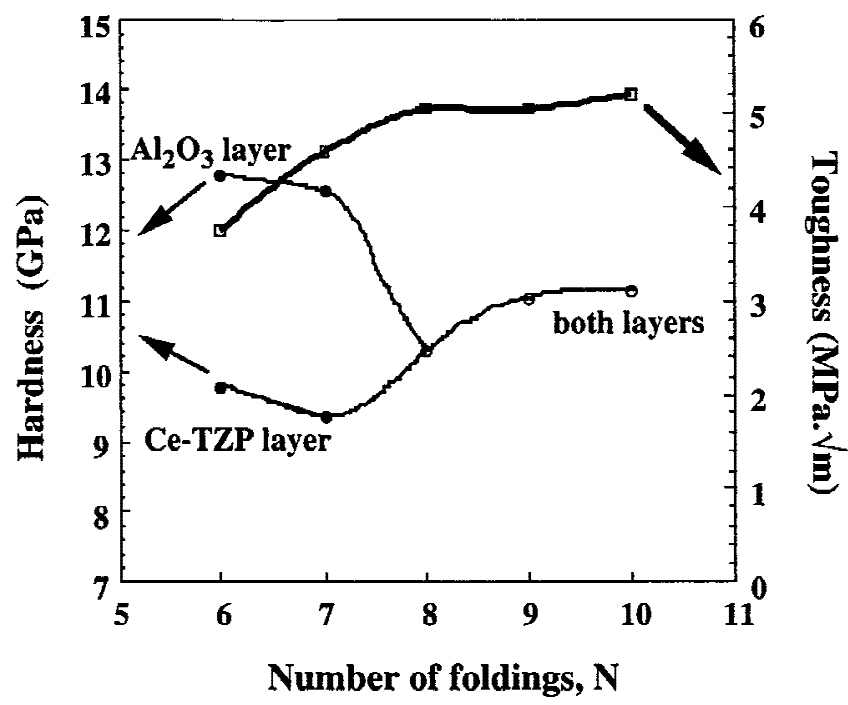

Fig. 12. Toughness and hardness of sample $\mathrm{B}$ at $200^{\circ} \mathrm{C}$ as a function of $N$. Solid circles (for hardness values) are the indents in single-phase layers, whereas open circles represent the indents encompassing both layers. Indents in either phase gave similar results for toughness.

cussed in paper II. ${ }^{12}$ Therefore, the cellular structure and the thinner layers should not increase the tendency for transformation within the composite, according to the thermal-stress argument (the previously given factor (ii)). In terms of physical barriers to transformation, we note that all the composites have a similar layer thickness after the same number of foldings (see paper I, Fig. 5), ${ }^{11}$ so the volume density of phase interface between $\mathrm{Ce}-\mathrm{TZP}$ and $\mathrm{Al}_{2} \mathrm{O}_{3}$ that acts as the barrier (such that the density is proportional to the reciprocal layer thickness) is the same in both the laminate and cellular composites. Thus, no difference is expected between layered and cellular microstructures from this argument (factor (i)) either. Moreover, ReyesMorel and Chen ${ }^{5}$ established that the dispersion of a second phase that interrupts the phase transformation has a tendency to suppress the transformation. Thus, a mere decrease in thickness should have suppressed the transformation and should not cause the increase of transformation, as we observed. This determination leads us to believe that the effect of a stress concentrator (factor (iii)) is dominant and that the cellular structure of $\mathrm{Al}_{2} \mathrm{O}_{3}$ and the thinner layers provide effective stress raisers that cause the transformation of zirconia at more locations. Such stress concentrators have the effect of generating higher strength and toughness in the cellular material. These stress raisers possibly are the corners, edges, and other asperities of the $\mathrm{Al}_{2} \mathrm{O}_{3}$-phase regions that have a high modulus and sufficiently high aspect ratios. That is, rodlike or platelike $\mathrm{Al}_{2} \mathrm{O}_{3}$ inclusions are most effective in triggering transformation in the surrounding Ce-TZP matrix. The number of these stress concentrators is expected to increase with decreasing thickness and especially with the layer-to-cellular transition, which is consistent with the transformation data that have been observed in our work. This result also is consistent with the fact that sample $\mathrm{B}$ is the strongest, in that sample $\mathrm{B}$ has the greatest tendency to form elongated $\mathrm{Al}_{2} \mathrm{O}_{3}$ inclusions. ${ }^{11}$

Our strength data show a general correlation with the amount of transformation. Therefore, the above-mentioned discussion on the effect of stress raisers should be applicable for explaining the strength data. Interestingly, we found that the strength in the $z$-direction is higher than that in the $x$-direction. Higher strength and transformation may originate from a larger shielding zone or more stress concentrators. To picture the phase region and the shielding zone of $\mathrm{Ce}-\mathrm{TZP}$, we construct, in Fig. 13 , flattened Ce-TZP phase regions that have dimensions $L_{x}$ and $L_{z}$ in the two planar directions (the $x$ - and $z$-directions, respectively), with $L_{x}>L_{z}$, because of rolling. For a layered composite, the two cracks that propagate along the $\boldsymbol{y}$-axis but on either the $x$-plane or $z$-plane will encounter the same phase fraction and interface density but different heights of the zirconia phase, different shielding-zone widths, and different numbers of stress concentrators. From a dimensional argument, we can state that the pertinent dimension is the length scale of the $\mathrm{Ce}-\mathrm{TZP}$ region normal to the crack plane, because autocatalytic transformation becomes dominant once the transformation is triggered near the crack plane in an isolated Ce-TZP region. Therefore, for the crack on the $x$-plane, the height of the 


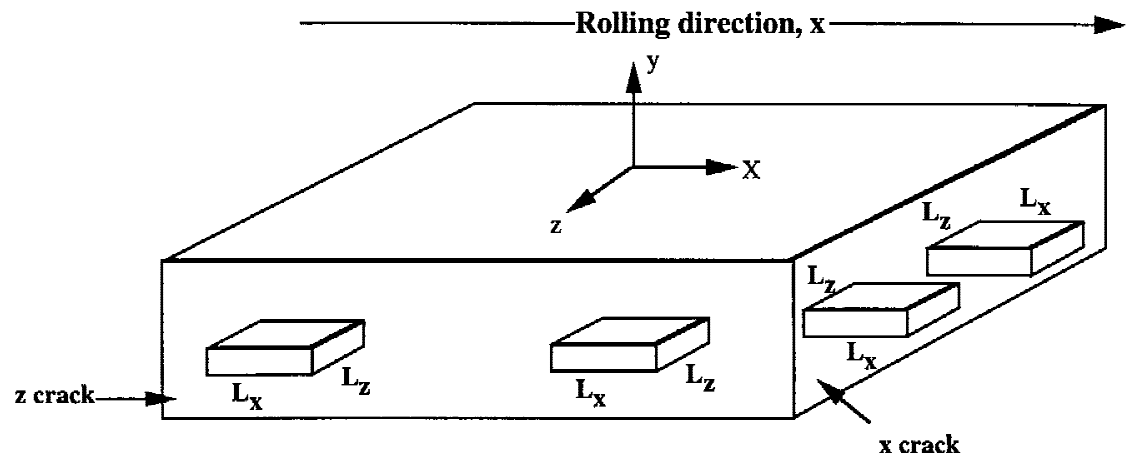

Fig. 13. Schematic of the composite, showing flattened phase regions with dimensions $L_{x}$ and $L_{z}\left(L_{x}>L_{z}\right)$, cut by the $x$-and $z$-direction crack fronts.

Ce-TZP region normal to the crack and, hence, the width of the transformation shielding zone are both commensurate with $L_{x}$, and the number of stress concentrators is related to $1 / L_{x}$. Similarly, for the crack on the $z$-plane, the height of the Ce-TZP region normal to the crack and, hence, the width of the transformation shielding zone are proportional to $L_{z}$, and the number of stress concentrators is related to $1 / L_{z}$. If the higher strength originates from a larger Ce-TZP phase region and a thicker transformation zone, then the strength normal to the $x$-plane should be higher, according to the dimensional argument. However, this result is contrary to our observation. Thus, the higher strength of the z-plane is consistent with a greater number of stress concentrators for such configurations.

The above-described analysis suggests that the composites that are most prone to stress-assisted Ce-TZP transformation and have the best mechanical performance are those with the greatest number of stress raisers from the $\mathrm{Al}_{2} \mathrm{O}_{3}$ inclusions. This observation is consistent with many reports that state the conventional Ce-TZP/Al ${ }_{2} \mathrm{O}_{3}$ composites with dispersed $\mathrm{Al}_{2} \mathrm{O}_{3}$ do not have high toughness, ${ }^{6,7}$ because the $\mathrm{Al}_{2} \mathrm{O}_{3}$ inclusions in these composites generally are equiaxed and are not effective stress concentrators. Our results also suggest, as we mentioned in the introduction, that the length of the Ce-TZP phase region normal to the crack plane does not need to be excessively long. Typically, the aspect ratio of Ce-TZP in this study is on the order of 10 or more, even in cellular composites. Thus, a relatively large coherent length $\left(L_{x}\right.$ and $\left.L_{z}\right)(\sim 40 \mu \mathrm{m})$ can still be maintained at a very fine layer thickness of $4 \mu \mathrm{m}$. Such a length $(40 \mu \mathrm{m})$ seems to be sufficient to allow the transformation to reach its fullest extent. (Otherwise, the strength on the $x$-plane, with longer $L_{x}$, should have been higher than the strength in the $z$-plane, with a shorter $L_{z}$.) Overall, cellular composites, especially those with $\mathrm{Al}_{2} \mathrm{O}_{3}$ as the included phase, seem to satisfy the above-stated requirements very well. Provided a strong, traction transmitting interface is maintained between $\mathrm{Ce}-\mathrm{TZP}$ and $\mathrm{Al}_{2} \mathrm{O}_{3}$ in this microstructure, such composites should provide superior strength and toughness, compared to layered composites and conventional, dispersed-phase composites.

\section{(2) Strength-R-Curve-Transformation Correlation}

The $R$-curves that are measured from the crack on the $x$ plane propagates in the $y$-direction show a systematic increase with decreasing layer thickness and with microstructure transition. This trend is qualitatively consistent with the previous discussion. We have not performed any theoretical modeling to simulate the $R$-curves based on a transformation model. However, because the shape of the $R$-curves is known to have an important effect on the stability of crack growth (and, hence, the strength), we will test this strength- $R$-curve relation in the following discussion. This examination will provide another rationale for the high strength that is observed, by demonstrating the advantage of a steep $R$-curve in promoting crack stability.
The condition of instability of a crack is given by ${ }^{20}$

$$
\left(\frac{\partial K}{\partial a}\right)_{\Delta_{\mathrm{T}}}=\frac{\partial K_{R}}{\partial \Delta a}
$$

where $K$ is the applied stress intensity factor (which is a function of crack length) and $K_{R}$ is the material $R$-curve property, which is dependent on the crack length. This condition can be estimated graphically by drawing, on the same graph, (i) $K$ curves at various loads or stresses and (ii) the $R$-curve, to find the $K$-curve that is tangent to the $R$-curve. The load for such $K$-curves then determines the strength of the sample. In reality, the slope of the load line also is dependent on the compliance of the loading train and is given by the following expression: ${ }^{20}$

$$
\left(\frac{\partial K}{\partial a}\right)_{\Delta_{\mathrm{T}}}=P f^{\prime}+\frac{P f^{\prime}}{C+C_{\mathrm{M}}}
$$

where $P$ is the applied load, $f$ a function of the crack length $a$ (computed from $K$, using $K=f(a) P), C$ the compliance of the sample, $C_{\mathrm{M}}$ is the compliance of the machine, and $\Delta_{\mathrm{T}}$ the total displacement of the specimen and the load frame. Because we are interested in estimating the strength of an unnotched sample, the compliance required here is that of a very small crack length (on the order of processing/machining flaw, taken to be $50 \mu \mathrm{m}$ in length). This compliance and $f$ can be computed from Eqs. (1) and (3). For the ease of calculations, a secondorder polynomial was fitted to the compliance function (Eq. (1)) and a square-root function of $a / w$ was fitted to calculate $f$ (Eq. (3)) for $a / w=0.01-0.05$. Then, $f^{\prime}$ and $C^{\prime}$ were calculated and their values were substituted into Eq. (8) and integrated over the crack length $a$ to give an applied $K$ as a function of $a$. To determine the load at failure for the unnotched samples, the $R$-curves were shifted to an initial crack length $a_{\circ}$ of $50 \mu \mathrm{m}$. Then, the load at which the applied $K$ is tangent to the $R$-curve is determined in the fashion shown in the example of Fig. 14(a). From this load, the stress at which the crack growth becomes unstable can be calculated. This procedure was performed for all the $R$-curves, and the results are plotted as a function of $N$ in Fig. 14(b).

Despite reservations that the measured $R$-curves of notched samples are a good measure of the $R$-curves of short, natural flaws ${ }^{21}$ the above-described procedure allows us to assess the importance of the $R$-curve in the determination of strength. Note that, because the $R$-curve was measured on the $x$-plane, the only valid comparison is with the $x$-plane strength of sample B in Fig. 5. Although we do not have the $x$-plane strength data of sample A to compare, the predicted trend of the strength for this material is comparable to that of the z-plane strength data shown in Fig. 5(b) for sample A at room temperature. We also see that sample A has a lower strength than sample $\mathrm{B}$, which is again consistent with the experimental data (albeit on a different plane). According to the stability argument, such higher strengths are a direct result of the steeper $R$-curves that are obtained at higher $N$. 

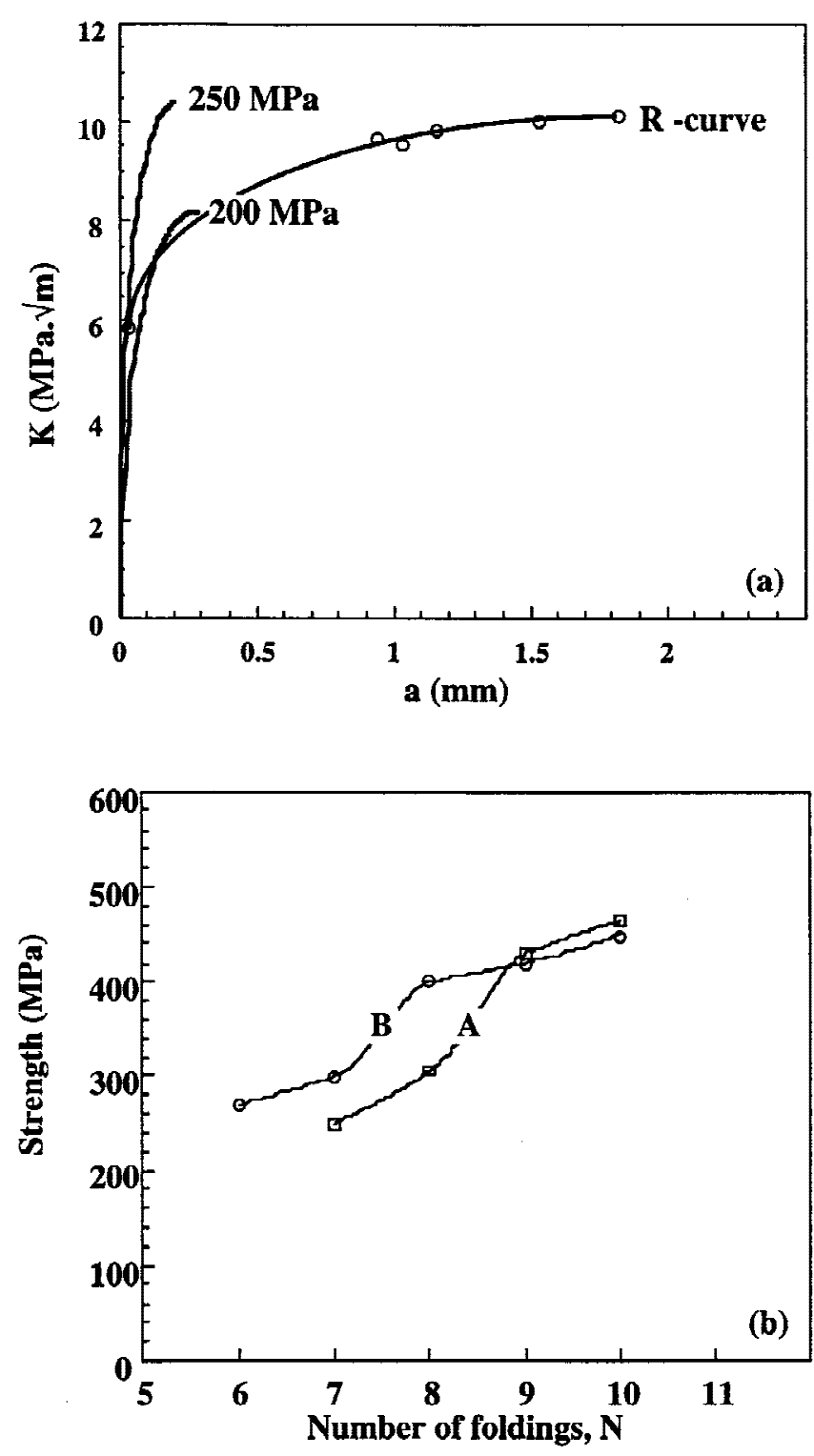

Fig. 14. (a) Typical tangency construction to predict the fracture strength from the $R$-curve, assuming a flaw size of $50 \mu \mathrm{m}$; the fracture stress when the tangency condition is met is 200-250 MPa. (b) Predicted fracture strengths at room temperature, from the tangency construction for samples $\mathrm{A}$ and $\mathrm{B}$, as a function of $N$.

The strength (1.1 GPa at the maximum) and toughness (16 $\mathrm{MPa} \cdot \mathrm{m}^{1 / 2}$ ) observed in our study, in addition to the very high hardness $(11.5 \mathrm{GPa})$, are both located at the high end of the range of the mechanical properties that have been reported for various $\mathrm{Ce}-\mathrm{TZP} / \mathrm{Al}_{2} \mathrm{O}_{3}$ composites. The highest toughness of this system-17.5 $\mathrm{MPa} \cdot \mathrm{m}^{1 / 2}$ — was reported by Marshall and co-workers. ${ }^{8,9}$ However, no strength data were reported in their paper and, according to our understanding via private communication, these investigators felt that their samples were too few to warrant strength measurements, given the prospect of processing flaws that may be present. The highest strength of this system- $0.85 \mathrm{GPa}$ - was reported by Cutler et al. ${ }^{7}$ The toughness of their material was $8.3 \mathrm{MPa} \cdot \mathrm{m}^{1 / 2}$. More commonly, there is a trend that a higher toughness is obtained at the cost of a lower strength, and vice versa. ${ }^{6,7,22,23}$ This phenomenon usually is caused by the more-gradual $R$-curve that is associated with high-toughness materials, in which the high toughness is achieved by increasing the width of the shielding zone that can be fully developed only after considerable crack propagation. In our materials, however, higher strength and tough- ness both are obtained as the microstructure is refined. Because repeated folding and rolling increase the density of stress concentrators that trigger transformation toughening, they can cause both a higher steady-state toughness and a steeper $R$ curve at the same time, which leads to a higher strength. Moreover, repeated folding and rolling are likely to reduce the size of the processing flaws and flatten them so that they are harmless for the strength measurements on the $x$-plane and the $z$ plane. Thus, these two reasons can explain why, compared to other methods of producing layered and particulate composites, our processing method seems to be advantageous in delivering good mechanical performance.

\section{Conclusions}

(1) The amount of Ce-TZP that is transformed during fracture increases as the discontinuity or inhomogeneity in the Ce-TZP/Al ${ }_{2} \mathrm{O}_{3}$ phases increases, presumably because of the increasing number of stress concentrators at the $\mathrm{Al}_{2} \mathrm{O}_{3}$ asperities in the cellular microstructure. This relation can be achieved by decreasing the layer thickness or breaking down the layered microstructure into a cellular geometry, preferably with $\mathrm{Al}_{2} \mathrm{O}_{3}$ as the encased phase.

(2) The $R$-curve also is related to the microstructure. This parameter, in turn, controls the flexural strength of the composites. The $R$-curve steepens, and the strength increases, as the microstructure refines and as a microstructure with $\mathrm{Al}_{2} \mathrm{O}_{3}$ inclusions is obtained. The strength of the composites further increases at lower temperature with enhanced transformation. A cellular composite (sample B) reached a strength of $550 \mathrm{MPa}$ at room temperature and $1.1 \mathrm{GPa}$ at $-50^{\circ} \mathrm{C}$. The highest measured fracture toughness was $16 \mathrm{MPa} \cdot \mathrm{m}^{1 / 2}$.

(3) The hardness of the composites becomes spatially homogeneous as the microstructure is refined. In Ce-TZP/Al ${ }_{2} \mathrm{O}_{3}$ composites, a constant value of $11.5 \mathrm{GPa}$ can be obtained in both laminate and cellular composites with a finer layer thickness $(<10 \mu \mathrm{m})$.

(4) The optimal Ce-TZP/Al ${ }_{2} \mathrm{O}_{3}$ composite for mechanical performance is that with dispersed $\mathrm{Al}_{2} \mathrm{O}_{3}$ regions with a high aspect ratio. Deformation processing in the colloidal state, using high-density $\mathrm{Ce}-\mathrm{TZP}$ and $\mathrm{Al}_{2} \mathrm{O}_{3}$ slurries, is an effective method for producing such a microstructure. The good sinterability of composites that are prepared by the above-described method is a further advantage.

Acknowledgment: The authors gratefully acknowledge Dr. Desidiro Kovar for helping with the $R$-curve measurements.

\section{References}

${ }^{1}$ I-W. Chen, "Model of Transformation Toughening in Brittle Materials," $J$. Am. Ceram. Soc., 74 [10] 2564-72 (1991).

${ }^{2}$ D. B. Marshall, A. G. Evans, and M. Drory,"Transformation Toughening in Ceramics"; pp. 289-307 in Fracture Mechanics of Ceramics, Vol. 6, Measurements, Transformations, and High-Temperature Fracture. Edited by R. C. Bradt, A. G. Evans, D. P. H. Hasselman, and F. F. Lange. Plenum Press, New York, 1983.

${ }^{3}$ R. M. McMeeking and A. G. Evans, "Mechanics of TransformationToughening in Brittle Materials," J. Am. Ceram. Soc., 65 [5] 242-46 (1982).

${ }^{4}$ B. Budiansky, J. W. Hutchinson, and J. C. Lambropoulos, "Continuum Theory of Dilatant Transformation Toughening in Ceramics," Int. J. Solids Struct., 19 [4] 337-55 (1983).

${ }^{5}$ P. E. Reyes-Morel and I-W. Chen, "Transformation Plasticity of $\mathrm{CeO}_{2}$ Stabilized Tetragonal Zirconia Polycrystals: I, Stress Assistance and Autocatalysis," J. Am. Ceram. Soc., 71 [5] 343-53 (1988).

${ }^{6} \mathrm{~K}$. Tsukuma and T. Takahata, "Mechanical Property and Microstructure of TZP and TZP/ $/ \mathrm{Al}_{2} \mathrm{O}_{3}$ Composites"; pp. 123-35 in Materials Research Society Symposium Proceedings, Vol. 78, Advanced Structural Ceramics. Edited by P. F. Becher, M. V. Swain, and S. Sōmiya. Materials Research Society, Pittsburgh, PA, 1987.

${ }^{7}$ R. A. Cutler, R. J. Mayhew, K. M. Prettyman, and A. V. Virkar, "HighToughness Ce-TZP/Al $\mathrm{O}_{3}$ Ceramics with Improved Hardness and Strength," $J$. Am. Ceram. Soc., 74 [1] 179-86 (1991).

${ }^{8}$ D. B. Marshall, J. J. Ratto, and F. F. Lange, "Enhanced Fracture Toughness in Layered Microcomposites of $\mathrm{Ce}-\mathrm{ZrO}_{2}$ and $\mathrm{Al}_{2} \mathrm{O}_{3}$, , J. Am. Ceram. Soc., 74 [12] 2979-87 (1991). 
${ }^{9}$ D. B. Marshall, "Design of High-Toughness Laminar Zirconia Composites," Am. Ceram. Soc. Bull., 71 [6] 969-73 (1992)

${ }^{10}$ E. Lucchini and O. Sbaizero, "Alumina/Zirconia Multilayer Composites Obtained by Centrifugal Consolidation," J. Eur. Ceram. Soc., 15, 975-81 (1995).

${ }^{11}$ M. Menon and I-W. Chen, "Bimaterial Composites via Colloidal Rolling Technique: I, Microstructure Evolution," J. Am. Ceram. Soc., 82 [12] 3413-21 (1999).

${ }^{12}$ M. Menon and I-W. Chen, "Bimaterial Composites via Colloidal Rolling Technique: II, Sintering Behavior and Thermal Stresses," J. Am. Ceram. Soc., 82 [12] 3422-29 (1999).

${ }^{13}$ P. E. Reyes-Morel, J. S. Cherng, and I-W. Chen, "Transformation Plasticity of $\mathrm{CeO}_{2}$-Stabilized Tetragonal Zirconia Polycrystals: II, Pseudoelasticity and Shape Memory Effect," J. Am. Ceram. Soc., 71 [8] 648-57 (1988).

${ }^{14}$ T. L. Anderson, Fracture Mechanics: Fundamentals and Applications. CRC Press, Ann Arbor, MI, 1991.

${ }^{15}$ K. J. Bowman, P. E. Reyes-Morel, and I-W. Chen, "Texture from Deformation of Zirconia Containing Ceramics"; pp. 811-16 in Proceedings of the 8th International Conference on Textures in Materials. Edited by J. S. Kallend and G. Gottstein. The Metallurgical Society, Warrendale, PA, 1988.
${ }^{16} \mathrm{~K} . \mathrm{J}$. Bowman and I-W. Chen, "Transformation Textures in Zirconia," $J$. Am. Ceram. Soc., 76 [1] 113-22 (1993).

${ }^{17}$ G. R. Anstis, P. Chantikul, B. R. Lawn, and D. B. Marshall, "A Critical Evaluation of Indentation Techniques for Measuring Fracture Toughness: I, Direct Crack Measurements," J. Am. Ceram. Soc., 64 [9] 533-38 (1981).

${ }^{18}$ D. R. Mumm, D. B. Marshall, A. Griffin, C. W. Griffin, and C. S. Turner, "Hardness Variations in Multilayered $\mathrm{ZrO}_{2}-\mathrm{Al}_{2} \mathrm{O}_{3}$ Composites," J. Am. Ceram. Soc., 79 [5] 1416-18 (1996).

${ }^{19}$ K. B. Alexander, P. F. Becher, X.-L. Wang, and C.-H. Hsueh, "Internal Stresses and the Martensitic Start Temperature in Alumina-Zirconia Composites: Effects of Composition and Microstructure," J. Am. Ceram. Soc., 78 [2] 291-96 (1995).

${ }^{20}$ J. W. Hutchinson, Nonlinear Fracture Mechanics. Dept. of Solid Mechanics, TU, Denmark, 1980.

${ }^{21}$ B. Lawn, Fracture of Brittle Solids, 2 nd ed. Cambridge University Press, Oxford, U.K., 1993.

${ }^{22}$ M. V. Swain and L. R. F. Rose, "Strength Limitations of TransformationToughened Zirconia Alloys," J. Am. Ceram. Soc., 69 [7] 511-19 (1986).

${ }^{23}$ H. E. Lutz and N. Claussen, "Duplex Ceramics: II. Strength and Toughness," J. Eur. Ceram. Soc., 7 [3] 219-26 (1991). 